\title{
EFEITO DA ALTURA DE CORTE DAS PLANTAS NA PRODUTIVIDADE DE MATÉRIA SECA E EM CARACTERÍSTICAS BROMATOLÓGICAS DA FORRAGEM DE MILHO ${ }^{1}$
}

\author{
Effect of cutting height of plants on dry matter yield and on bromatologic \\ characteristics of corn forage
}

\author{
Ramon Correia de Vasconcelos², Renzo Garcia Von Pinho ${ }^{3}$, Adauton Vilela Rezende ${ }^{4}$, \\ Marcos Neves Pereira ${ }^{4}$, André Humberto de Brito ${ }^{3}$
}

\begin{abstract}
RESUMO
Este trabalho foi conduzido com o objetivo de avaliar a produção de matéria seca e a composição bromatológica da forragem de cultivares de milho submetidos a duas alturas de corte das plantas (altura $1-0,1 \mathrm{~m}$ e altura $2-0,8 \mathrm{~m}$ ) em três anos de cultivo no município de Lavras, MG. Os experimentos foram instalados em área experimental do Departamento de Agricultura da Universidade Federal de Lavras (UFLA) nas safras agrícolas 1998/1999, 1999/2000 e 2000/2001, empregando-se cinco cultivares de milho no primeiro ano e seis nos anos seguintes. Os experimentos foram conduzidos sob o delineamento de blocos casualizados em esquema fatorial 5 × 2 e 6 x 2, sendo cinco ou seis cultivares de milho e duas alturas de corte, com três repetições. Avaliaram-se as características produtividade de matéria seca (MS) e teores de proteína bruta (PB), fibra em detergente neutro (FDN) e fibra em detergente ácido (FDA) na MS. Detectou-se efeito significativo das alturas de corte em todas as características estudadas. Os teores de PB aumentaram e os de FDN e FDA diminuíram com a elevação da altura de corte das plantas. Comparando-se as duas alturas de corte, verificou-se que houve uma redução de 3,3 t.ha ${ }^{-1}$ na produtividade de MS, um aumento de $0,6 \%$ no teor de PB, uma redução de $4,4 \%$ no teor de FDN e uma redução de 3,9\% no teor de FDA com a elevação da altura de corte de 0,1 para $0,8 \mathrm{~m}$. Os resultados obtidos permitiram concluir que a elevação da altura de corte, embora tenha contribuído para a diminuição da produção de MS, proporcionou uma melhoria na qualidade da forragem em decorrência da parte mais fibrosa e menos digestível da planta de milho não ter sido colhida.
\end{abstract}

Termos para indexação: Proteína bruta, fibra em detergente neutro, fibra em detergente ácido.

\begin{abstract}
This work was conducted with the purpose of evaluating dry matter yield and the chemical nutritive composition of forage of corn cultivars submitted to cutting heights of the plants (height $1-0,1 \mathrm{~m}$, and height $2-0,8 \mathrm{~m}$ ) in three growing years. The experiments were set up in an experimental area of the Agriculture Department of the Federal University of Lavras (UFLA) in the agricultural crops of 1998/1999, 1999/2000 and 2000/2001, where five corn cultivars were utilized in the first year and six corn cultivars in the following years. The experiments were conducted in the randomized block design in a $5 \times 2$ and $6 \times 2$ factorial scheme, where as five and six corn cultivars and two cutting height, with three replications. The characteristics of dry matter yield (DMY), crude protein (CP), neutral detergent fiber (NDF) and acid detergent fiber (ADF) were evaluated. A significant effect was found for cutting heights in all characteristics evaluated. Crude protein contents increased and NDF and ADF contents decreased with the increase of the cutting height of the plants. Comparing the two cutting heights, it was found that there was a reduction in yield of 3.3 ton.ha $\mathrm{a}^{-1}$ for DMY, an increase of $0.6 \%$ in crude protein content, a reduction of $4.4 \%$ in the percent of NDF and a decrease of $3.9 \%$ in the percent of ADF. The results obtained allowed to conclude that the elevation of the cutting height, although had contributed to the decrease of dry matter yield provided, an improvement in forage quality, due to the most fibrous and least digestible part of the corn plant have not been harvested.
\end{abstract}

Index terms: Crude protein, neutral detergent fiber, acid detergent fiber.

(Recebido para publicação em 14 de maio de 2004 e aprovado em 18 de julho de 2005)

\section{INTRODUÇÃO}

Forrageiras para alimentação de vacas leiteiras devem conciliar a alta produção de matéria seca (MS) por área, maximizadora da taxa de lotação animal, com o alto valor nutritivo, capaz de reduzir a necessidade de alimentos concentrados por litro de leite produzido (REZENDE, 2001). O milho (Zea mays L.) é a espécie mais utilizada no Brasil para a produção de silagem de alta qualidade e seu uso tem sido incrementado na medida que proporciona a eficiência e a competitividade dos sistemas de produção de leite.

A cultivar de milho adaptada para a produção de grãos provavelmente também produzirá silagem de boa qualidade (STAPLES, 1994). Cultivares que apresentam de 40 a $50 \%$ de grãos na MS do material ensilado proporcionam silagens de boa qualidade (FARIA, 1986).

1. Parte da Tese apresentada à Universidade Federal de Lavras/UFLA, pelo primeiro autor, para obtenção do grau de Doutor

2. Departamento de Fitotecnia e Zootecnia, UESB, Vitória da Conquista, BA - 45.000-000.

3. Departamento de Agricultura, Universidade Federal de Lavras - Cx. P. 3037 - 37.200-000 - Lavras, MG.

4. Departamento de Zootecnia, Universidade Federal de Lavras - Cx. P. 3037 - 37.200-000 - Lavras, MG. 
Uma alternativa para aumentar o valor nutritivo e a qualidade da silagem de milho é elevar a altura de corte das plantas no momento da colheita, aumentando, dessa forma, a proporção de grãos no material ensilado. Porém, ainda são escassos estudos nessa área.

O milho pode ser ensilado de várias maneiras, entre elas: silagem da planta inteira e silagem da parte superior, como alimentos volumosos, e silagem de espigas e de grãos úmidos, como alimentos concentrados, ricos em energia.

Segundo Fancelli \& Dourado Neto (2000), no momento da colheita a planta deve ser cortada a uma altura de 10 centímetros do solo, podendo, se preferir, efetuar o corte a uma altura mais elevada. À medida que se aumenta a altura de corte, diminui-se o volume da massa ensilada, porém aumenta a qualidade do alimento, já que a participação de grãos no material ensilado é aumentada.

A silagem da parte superior das plantas de milho é indicada como uma nova opção, sendo obtida mantendose a ensiladeira o mais próximo possível da espiga com o objetivo de recolher somente a parte superior da planta de milho, constituindo-se numa silagem com alta participação de grãos na MS, possuindo menor conteúdo de fibra e maior conteúdo energético. Este tipo de silagem é recomendado em sistemas de produção que utilizam animais extremamente exigentes, como vacas de leite de alta produção e novilhos precoces, em virtude deste ser um alimento de melhor valor nutritivo e custo de produção mais elevado, por normalmente apresentar rendimento de 75 a $85 \%$ em relação a silagem de planta inteira (PIONEER SEMENTES, 1996).

Após avaliar a composição química e a digestibilidade in vivo das silagens de cultivares de milho, nos sistemas de planta inteira (altura de corte rente ao solo) e da parte superior (altura de corte na inserção da primeira espiga), Pereira et al. (1997) verificaram que os sistemas de colheita proporcionaram adequada conservação das silagens e não foram efetivos em promover alterações na composição química e na digestibilidade in vivo da MS, da fibra em detergente neutro (FDN) e da proteína bruta (PB) das silagens dos cultivares de milho avaliados.

Caetano (2001) avaliando cultivares de milhos colhidos em duas alturas de corte para produção de silagem em Jaboticabal (SP) verificou que a elevação da altura de corte melhorou a qualidade da forragem por causa da redução das frações colmo e folha e dos teores de fibra e do aumento da fração grão. Esse autor verificou uma produção de 14,7 t.ha ${ }^{-1}$ de MS quando o corte das plantas foi realizado a $5 \mathrm{~cm}$ do solo e de 10,9 t.ha $^{-1}$ de MS quando o corte das plantas foi realizado a $5 \mathrm{~cm}$ abaixo da primeira espiga.

Resultados de pesquisa desenvolvida nos Estados Unidos, apresentados por Lauer (1998), evidenciaram que a produção de MS é reduzida cerca de $15 \%$ quando a altura de corte é elevada de 15 para $45 \mathrm{~cm}$, a partir do nível do solo. No entanto, a produção de leite aumentou aproximadamente $12 \%$ para a mesma elevação na altura de corte, porque a parte mais fibrosa e menos digestível da planta de milho foi deixada no campo, resultando em uma redução de apenas $3 \%$ na produção estimada de leite por área.

Segundo Hutjens (2001), para cada $15 \mathrm{~cm}$ na elevação da altura de corte espera-se uma redução de $1 \%$ no teor de fibra em detergente ácido (FDA) do material colhido, sendo a redução na produção de MS obtida de aproximadamente $850 \mathrm{~kg} \cdot \mathrm{ha}^{-1}$.

Para Nussio et al. (2001), o retorno econômico por tonelada de MS por hectare é inferior para plantas colhidas na altura de corte mais elevada (abaixo da espiga), quando comparado com o obtido pelo corte rente ao solo. Deste modo, os autores questionam a viabilidade econômica da elevação da altura de corte das plantas de milho para produção de silagem. Segundo os mesmos autores, plantas colhidas em altura mais elevada devem contribuir não somente para aumentar a reciclagem da matéria orgânica no solo, garantindo condicionamento físico ao mesmo, mas também para retornar grandes quantidades de potássio (K) que se encontram nos internódios inferiores da planta. Ambas as contribuições são positivas para o estabelecimento de um programa duradouro de exploração de áreas para produção de milho para silagem, em anos subseqüentes, visando alta produtividade, e merecem avaliação econômica mais cuidadosa, levando em consideração a produção ao longo dos anos para justificar a recomendação.

Com este trabalho, objetivou-se avaliar as características agronômicas e a composição bromatológica da forragem de cultivares de milho submetidos a duas alturas de corte das plantas em três anos de cultivo.

\section{MATERIAL E MÉTODOS}

Foram avaliados em três safras agrícolas treze cultivares de milho de diferentes bases genéticas, ciclo e tipos de grãos, todas adaptadas à região Sul de Minas Gerais para o cultivo durante o período da primavera/verão (Tabela 1).

Ciênc. agrotec., Lavras, v. 29, n. 6, p. 1139-1145, nov./dez., 2005 
TABELA 1 - Características das cultivares avaliadas nos experimentos nas safras 1998/1999, 1999/2000 e 2000/2001. UFLA, Lavras, MG, 2004.

\begin{tabular}{lccccc}
\hline \multicolumn{1}{c}{ Cultivar } & Safra & Tipo de cultivar & Ciclo fenlógico & Tipo de grão & Empresa \\
\hline DKB 929 & $98 / 99$ & Híb. Simples mod. & Super precoce & Duro & Dekalb \\
DKB 333B & $98 / 99$ & Híb. simples mod. & Normal & Meio-dente & Dekalb \\
DKB 808 & $98 / 99$ & Híbrido triplo & Precoce & Semi-duro & Dekalb \\
DKB 747 & $98 / 99$ & Híbrido triplo & Normal & Semi-duro & Dekalb \\
DKB 444 & $98 / 99$ & Híbrido duplo & - & - & Dekalb \\
DKB 212 & $99 / 00$ & Híb. simples & Precoce & Semi-dentado & Dekalb \\
DKB 440 & $99 / 00$ & Híb. simples mod. & Tardio & Semi-dentado & Dekalb \\
AG 1051 & $99 / 00$ & Híbrido duplo & Normal & Dentado & Agroceres \\
AG 8080 & $99 / 00$ & Híbrido triplo & Precoce & Semi-duro & Agroceres \\
DKB 350 & $99 / 00$ & Híbrido triplo & Normal & Semi-duro & Dekalb \\
DKB 806 & $99 / 00$ & Híbrido triplo & Super precoce & Semi-duro & Dekalb \\
DKB 440 & $00 / 01$ & Híb. simples mod. & Tardio & Semi-dentado & Dekalb \\
DKB 280 & $00 / 01$ & Híb. simples mod. & Tardio & Semi-dentado & Dekalb \\
DKB 333B & $00 / 01$ & Híb. simples mod. & Normal & Meio-dente & Dekalb \\
AG 4051 & $00 / 01$ & Híbrido triplo & Normal & Dentado & Agroceres \\
AG 1051 & $00 / 01$ & Híbrido duplo & Normal & Dentado & Agroceres \\
AG 8080 & $00 / 01$ & Híbrido triplo & Precoce & Semi-duro & Agroceres \\
\hline
\end{tabular}

Os experimentos a campo foram conduzidos nas safras agrícolas de 1998/1999 (semeadura em 23 de novembro de 1998 e colheita em março de 1999), 1999/2000 (semeadura em 18 de novembro de 1999 e colheita em março de 2000) e 2000/2001 (semeadura em 28 de novembro de 2000 e colheita em março de 2001), em área experimental do Departamento de Agricultura (DAG), no campus da Universidade Federal de Lavras, em solo classificado como Latossolo Vermelho Escuro (LE), textura argilosa e declividade de $9 \%$.

O município de Lavras está situado na região Sul do Estado de Minas Gerais, a $21^{\circ} 14$ de latitude sul e $45^{\circ} 00$ de longitude oeste, com uma altitude de $920 \mathrm{~m}$ (BRASIL, 1992). O clima da região é do tipo mesotérmico de inverno seco (Cwb). A temperatura média é de $22,1^{\circ} \mathrm{C}$ no mês mais quente e de $15,8^{\circ} \mathrm{C}$ no mês mais frio, sendo a média anual de $19,4^{\circ} \mathrm{C}$. A pluviosidade média anual é de $1.530 \mathrm{~mm}$, com evaporação total no ano de $1.034,3 \mathrm{~mm}$ e umidade relativa anual de 76,2\% (BRASIL, 1992). As variações na temperatura e na precipitação média por decêndio, ocorridas durante a condução dos experimentos, estão apresentadas na Figura 1.

As condições da precipitação no município de Lavras, ocorridas durante o ciclo da cultura, ultrapassaram os $600 \mathrm{~mm}$ em cada um dos três anos de condução dos experimentos, suficientes para a boa produção da planta de milho, embora a distribuição da precipitação não tenha sido tão uniforme. Nesse mesmo período as temperaturas médias sempre estiveram acima de $20^{\circ} \mathrm{C}$ ou seja, acima do mínimo necessário para o bom desenvolvimento da cultura.

As semeaduras dos três experimentos foram realizadas na segunda quinzena de novembro. De acordo com os resultados apresentados nas análises de solo foram utilizados, como adubação de semeadura dos três experimentos, $400 \mathrm{~kg} \cdot \mathrm{ha}^{-1}$ da fórmula 08-28-16 + 0,5\% de zinco. A primeira adubação de cobertura foi realizada com aplicação de $300 \mathrm{~kg} \cdot \mathrm{ha}^{-1}$ da fórmula 20-00-20, quando as plantas atingiram entre quatro e seis folhas abertas. A segunda adubação de cobertura foi realizada quando as plantas atingiram entre sete e nove folhas abertas, utilizando $150 \mathrm{~kg}$ N.ha-1 de uréia. 

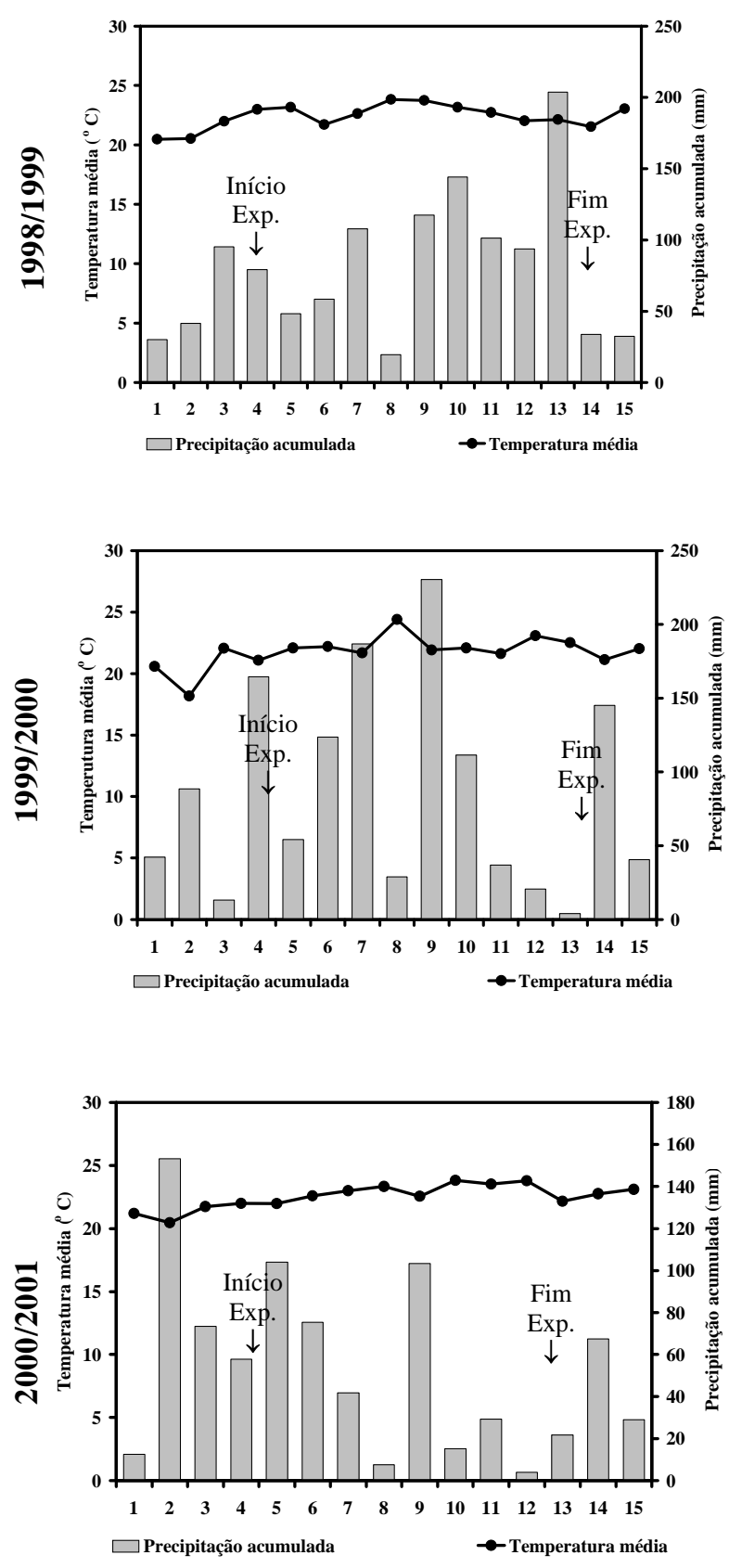

FIGURA 1 - Dados médios de temperatura e precipitação por decêndio, em Lavras-MG, no período de 01/11/1998 a 13/03/1999, de 01/11/1999 a 13/03/2000 e de 01/11/2000 a 13/03/2001. Dados obtidos no setor de Bioclimatologia da UFLA. Lavras-MG, 2002.
As semeaduras foram realizadas manualmente, utilizando-se oito sementes por metro linear, com espaçamento de $0,8 \mathrm{~m}$ entre linhas. Após a realização do desbaste, quando as plantas atingiram $20 \mathrm{~cm}$ de altura, foram deixadas, em média, 4,5 plantas por metro linear, objetivando um estande médio de 55.000 plantas.ha ${ }^{-1}$ por ocasião da colheita.

Para o controle das plantas invasoras, foi utilizado o herbicida Primextra (atrazine + metalaclor) na dosagem de 61 l.ha $^{-1}$ do produto comercial, aplicado em préemergência nos três experimentos.

Os tratos fitossanitários seguiram as recomendações técnicas para a cultura do milho empregadas nessa região. Em cada experimento, as plantas foram colhidas quando a linha de leite atingiu $2 / 3$ do grão.

Cada experimento foi conduzido sob o delineamento experimental de blocos ao acaso, em esquema fatorial $5 \times 2$ no primeiro ano e $6 \times 2$ nos dois anos subseqüentes, com três repetições, sendo as cinco cultivares avaliadas no primeiro ano (DKB 929, DKB 333 B, DKB 808, DKB 747 e DKB 444), as seis cultivares avaliadas no segundo ano (DKB 212, DKB 440, AG 1051, AG 8080, DKB 350 e DKB 806) e as seis cultivares avaliadas no terceiro ano (DKB 440, DKB 280, DKB 333, AG 4051, AG 1051 e AG 8080), em duas alturas de corte ( $0,1 \mathrm{~m}$ do solo e $0,8 \mathrm{~m}$ do solo). A parcela experimental foi constituída por quatro linhas de cinco metros de comprimento, perfazendo $16 \mathrm{~m}^{2}$ de área total, sendo considerada área útil da parcela as duas linhas centrais.

Inicialmente foi feita a determinação da produtividade de matéria verde. Para isso, todas as plantas da área útil das parcelas foram cortadas nas alturas de 0,1 e $0,8 \mathrm{~m}$, de acordo com o tratamento aplicado à parcela, e pesadas em balança do tipo dinamômetro. De posse da produção de matéria verde por parcela, estimou-se a produção por ha.

Em seguida, uma amostra de dez plantas selecionadas ao acaso na área útil de cada parcela foi agrupada, identificada e conduzida até o laboratório para ser triturada em picadeira de forragem e homogeneizada. Em seguida, foi retirado uma amostra de $300 \mathrm{~g}$, que foi seca em estufa de ventilação forçada a uma temperatura de $55^{\circ}$ $\mathrm{C}$ até a obtenção de peso constante. Posteriormente, essa amostra foi moída em moinho tipo Willey, com peneira de 1 $\mathrm{mm}$, para a determinação da matéria seca a $105^{\circ} \mathrm{C}$ (AACC, 1976) e realização das análises bromatológicas.

Foram avaliadas as seguintes características agronômicas e bromatológicas:

- Produtividade de MS: valor obtido após a

Ciênc. agrotec., Lavras, v. 29, n. 6, p. 1139-1145, nov./dez., 2005 
correção do teor de $\mathrm{MS}$ obtido a $55^{\circ} \mathrm{C}$ pelo teor de MS a $105^{\circ} \mathrm{C}$. De posse da produção de MS por parcela, estimouse a produção por ha.

- Teor de proteína bruta (PB): foi determinado o teor de nitrogênio utilizando-se o aparelho de destilação a vapor micro-Kjedahl, conforme AOAC (1970). O teor de proteína bruta foi calculado utilizando-se o fator de conversão 6,25.

- Teores de fibra em detergente neutro (FDN) e em detergente ácido (FDA): foram determinados por análise não seqüencial, segundo metodologia descrita por Soest et al. (1991). Na determinação da FDN utilizaram-se 0,5 g de sulfito de sódio e $200 u l$ de alfa amilase.

As determinações bromatológicas das forragens foram realizadas no Laboratório de Nutrição Animal da Universidade Federal de Lavras. Todas as análises foram executadas em duplicatas.

As características agronômicas e bromatológicas obtidas foram submetidas à análises de variância, utilizando o programa estatístico SAS (SAS INSTITUTE, 1995). As médias foram comparadas pelo teste de "F".

A análise de variância foi realizada de acordo com o seguinte modelo:

$$
Y_{i j k l}=m+B_{i}+C(A)_{j k}+D_{1}+e_{i j k l}
$$

Em que:

$\mathrm{Y}_{\mathrm{ijk} \mathrm{l}}$ : valor observado no bloco "i $\mathrm{i}$ ", no cultivar " $\mathrm{j}$ ” dentro do ano "k"; na altura "l";

$\mathrm{m}$ : média geral;

$B_{i}$ : efeito do bloco "i", sendo $i=1,2$ e 3 ;

$\mathrm{C}(\mathrm{A})_{\mathrm{jk}}$ : efeito do cultivar " $\mathrm{j}$ ” dentro do ano " $\mathrm{k}$ ", sendo $\mathrm{j}=1,2,3 \ldots$, e 17 e $\mathrm{k}=1,2$ e 3 ;

$\mathrm{D}_{1}$ : efeito da altura de corte " $\mathrm{l}$ ", sendo $1=1$ e 2 ;

$\mathrm{e}_{\mathrm{ijkl}}$ : erro experimental associado aos valores observados, que por hipótese tem distribuição normal com média zero e variância $\mathrm{s}^{2}$.

\section{RESULTADOS E DISCUSSÃO}

As médias de produtividade de MS e teores de PB, FDN e FDA na MS do milho, nas duas alturas de corte estudadas (0,1 e 0,8 m), assim como o erro padrão da média (EPM), os valores dos níveis descritivos $(\mathrm{Pr}>\mathrm{F})$ e dos coeficientes de variação (CV) de suas respectivas análises de variância, são apresentados na Tabela 2. Foi constatado, para todas as variáveis, efeito significativo $(\mathrm{P}<0,0001)$ das alturas de corte.

A precisão experimental avaliada pelo coeficiente de variação $(\mathrm{CV})$ variou entre as características, sendo considerada boa, com valores sempre inferiores a $16 \%$. A maior estimativa observada foi para FDA $(15,59 \%)$ e a menor, para $\mathrm{PB}(6,64 \%)$.

Para a produtividade de MS observou-se maior rendimento naquelas plantas colhidas a $0,1 \mathrm{~m}$ de altura do solo em relação ao corte realizado a $0,8 \mathrm{~m}$ (Tabela 2). $\mathrm{Na}$ altura de corte de $0,1 \mathrm{~m}$, as cultivares produziram 3,3 tha $^{-1}$ de MS a mais que a média de produtividade obtida na altura de corte de $0,8 \mathrm{~m}$, o que representa uma redução de $17,7 \%$ na produtividade de MS quando se eleva a altura de corte de $0,1 \mathrm{~m}$ para $0,8 \mathrm{~m}$. É importante enfatizar, ainda, que os custos para a produção da forragem são os mesmos em ambas as alturas de corte.

Esses resultados estão de acordo com os encontrados por Caetano (2001), que verificou redução de 25,6\% na produtividade de MS quando a altura média de corte aumentou de $0,5 \mathrm{~m}$ para aproximadamente $0,8 \mathrm{~m}$. Resultados semelhantes também foram obtidos por Lauer (1998), que observou redução de 15\% na produtividade de MS quando a altura de corte foi elevada de $0,15 \mathrm{~m}$ para 0,45 $\mathrm{m}$.

Há que se considerar as vantagens obtidas com a melhoria nas condições físicas (aumento da reciclagem da matéria orgânica) e químicas (retorno de quantidades consideráveis de $\mathrm{K}$ que se encontram nos internódios inferiores da planta) do solo quando se eleva a altura de corte das plantas em função da quantidade de palhada que fica no campo (NUSSIO et al., 2001).

As alturas de corte afetaram significativamente os teores de PB na MS das cultivares de milho, registrandose valores de 7,30 e 7,93\% para plantas colhidas a 0,1 e 0,8 $\mathrm{m}$ do solo, respectivamente (Tabela 2). Isso representa um aumento de $10,9 \%$ no teor de PB quando se eleva a altura de corte de $0,1 \mathrm{~m}$ para $0,8 \mathrm{~m}$, o que pode ser explicado pelo efeito de concentração da PB na MS, já que a parte basal da planta de milho, que é constituída basicamente de colmo, possui maior concentração de fibras e menor de $\mathrm{N}$ total, consequientemente, menor teor de PB. No entanto, Caetano (2001) não verificou diferença significativa entre as médias dos teores de PB das plantas de milho colhidas nas alturas de corte $0,5 \mathrm{~m}$ e $0,8 \mathrm{~m}$.

De um modo geral, os baixos teores de PB das cultivares de milho indicam a necessidade de uma suplementação com concentrados protéicos adicionados à silagem.

A altura de corte também afetou significativamente os teores médios de FDN para as cultivares de milho testadas (Tabela 2). A diminuição dos teores de FDN quando se elevou a altura de corte de 0,1 para $0,8 \mathrm{~m}$ foi de $8,8 \%$. 
TABELA 2 - Produtividade de matéria seca (MS) e teores de proteína bruta (PB), fibras em detergente neutro (FDN) e ácido (FDA) na MS de cultivares de milho avaliadas em três anos de cultivo e em duas alturas de corte (UFLA, LavrasMG, 2004).

\begin{tabular}{|c|c|c|c|c|c|}
\hline \multirow{2}{*}{ Variável } & \multicolumn{2}{|c|}{ Altura de corte (m) } & \multirow{2}{*}{ EPM } & \multirow{2}{*}{$\operatorname{Pr}>\mathbf{F}$} & \multirow{2}{*}{$\mathrm{CV}(\%)$} \\
\hline & 0,1 & $\mathbf{0 , 8}$ & & & \\
\hline MS (t.ha $\left.{ }^{-1}\right)$ & 18,60 & 15,32 & 0,32 & $<0,0001$ & 13,46 \\
\hline $\mathrm{PB}(\%)$ & 7,30 & 7,93 & 0,07 & $<0,0001$ & 6,64 \\
\hline FDN $(\%)$ & 50,16 & 45,75 & 0,61 & $<0,0001$ & 10,89 \\
\hline $\operatorname{FDA}(\%)$ & 25,87 & 22,00 & 0,41 & $<0,0001$ & 15,59 \\
\hline
\end{tabular}

Essa redução pode ser explicada pela diminuição da participação da fração fibrosa e aumento da proporção de grãos na MS das plantas colhidas na altura de corte mais elevada.

Em trabalhos realizados na região de Lavras, $\mathrm{MG}$, Fonseca (2000), Melo et al. (1998) e Villela (2001) verificaram variação de 43,45 a $60,98 \%$, de 44,55 a $66,54 \%$ e de 41,70 a $46,80 \%$, respectivamente, para os teores de FDN, em plantas colhidas a $0,1 \mathrm{~m}$ do solo, o que está de acordo com os resultados encontrados neste trabalho. Por outro lado, Caetano (2001) também verificou que as plantas colhidas na maior altura de corte $(0,8 \mathrm{~m})$ apresentaram teores médios de FDN inferiores àqueles obtidos para as plantas colhidas na menor de corte $(0,1 \mathrm{~m})$.

$\mathrm{O}$ teor de FDN, além de ser uma característica própria de cada cultivar de milho, pode sofrer influência de outros fatores. Na metodologia utilizada para sua determinação, a utilização correta de uma amilase termo-resistente elimina uma possível contaminação por amido, o que poderia resultar na obtenção de valores mais elevados de FDN.

De um modo geral, os valores encontrados para FDN nesse experimento podem ser considerados bons, já que níveis de FDN na forragem de milho menores que 50\% proporcionam silagens de boa qualidade (CRUZ \& PEREIRA FILHO, 2001).

A altura de corte afetou significativamente os teores médios de FDA na MS das cultivares de milho. A variação observada para os teores de FDA foi de $25,87 \%$ quando o corte das plantas foi realizado a $0,1 \mathrm{~m}$ do solo e de $22,00 \%$ quando o corte das plantas foi realizado a $0,8 \mathrm{~m}$ do solo (Tabela 2).

A diminuição dos teores de FDA de $14,85 \%$ indica que grande parte da FDA (fração não digestível da fibra) está presente na parte inferior da planta de milho e pode ser explicado pela redução da participação da fração fibra das partes vegetativas e pelo aumento da proporção de grãos na MS da planta inteira dos cultivares colhidos na maior altura de corte.

Em trabalhos realizados na região de Lavras, MG, Melo et al. (1998) e Villela (2001) verificaram variação de FDA de 22,66 a $31,06 \%$ e 24,48 a $27,49 \%$, respectivamente, quando as plantas de milho foram colhidas a $0,1 \mathrm{~m}$ do solo.

A FDA indica a quantidade de fibra que não é digestível, sendo um indicador do valor energético da forragem e/ou silagem do milho. Quanto menor o seu valor, maior o valor energético do alimento. Na média, um bom teor de FDA na forragem e/ou silagem de milho fica ao redor de 30\% (PIONEER SEMENTES, 1993), o que coloca todas as cultivares testadas dentro de padrões aceitáveis, levando em consideração que todas as médias se situaram nesse patamar e abaixo dele nas duas alturas de corte avaliadas.

As vantagens conseguidas com a elevação da altura de corte precisariam compensar as perdas de produtividade de MS para que a elevação na altura de corte das plantas de milho pudesse ser uma prática recomendada. Assim, a determinação dos custos de produção das silagens obtidas a partir de diferentes alturas de corte das plantas, bem como a realização de uma análise econômica, seriam instrumentos auxiliares para a tomada de decisão quanto ao sistema de manejo a ser adotado.

\section{CONCLUSÕES}

A elevação na altura de corte de $0,1 \mathrm{~m}$ para $0,8 \mathrm{~m}$, embora tenha contribuído para diminuir a produção de MS, proporcionou uma melhoria na qualidade da forragem, em decorrência da parte mais fibrosa e menos digestível da planta de milho não ter sido colhida. 


\section{REFERÊNCIAS BIBLIOGRÁFICAS}

AMERICAN ASSOCIATION OF CEREAL CHEMISTS. Approved methods of the American Association of Cereal Chemists. 7. ed. Saint Paul, 1976. 256 p.

ASSOCIATION OF OFFICIAL ANALYTICAL CHEMISTS. Official methods of analyses of the Association of Official

Analytical Chemists. 11. ed. Washington, 1970. v. 1, 1015 p.

BRASIL. Ministério da Agricultura e Reforma Agrária. Normais climatológicas 1961-1990. Brasília, 1992. 84 p.

CAETANO, H. Avaliação de onze cultivares de milho colhidos em duas alturas de corte para produção de silagem. 2001. $178 \mathrm{f}$. Tese (Doutorado em Zootecnia) Universidade Estadual Paulista, Jaboticabal, 2001.

CRUZ, J. C.; PEREIRA FILHO, I. A. Cultivares de milho para silagem. In: CRUZ, J. C. (Ed.). Produção e utilização de silagem de milho e sorgo. Sete Lagoas: EMBRAPA Milho e Sorgo, 2001. p. 11-37.

FANCELLI, A. L.; DOURADO NETO, D. Produção de milho. Guaíba: Ed. Agropécuária, 2000. 360 p.

FARIA, V. P. Técnicas para produção de silagem. In: CONGRESSO BRASILEIRO DE PASTAGENS, 8., 1986, Piracicaba. Anais... Piracicaba: FEALQ, 1986. p. 114-119.

FONSECA, A. H. Características químicas e agronômicas associadas à degradabilidade da silagem de milho. 2000. 93 p. Dissertação (Mestrado em Fitotecnia) - Universidade Federal de Lavras, Lavras, 2000.

HUTJENS, M. Selecting corn silage varieties. Disponível $\mathrm{em}: 1^{-}-2<\mathrm{htp}$ ://dairynet.outreach uiuc.edu ifulltest.cfm?section=1 $\&$ documentI $=408$ ? . Acesso em: 20 jan. 2001 .

LAUER, J. Corn silage yield and quality trade-offs when changing cutting height. Agronomy Advice, 1998. Disponível emi <http:///corn.agronomy.wisc.edut

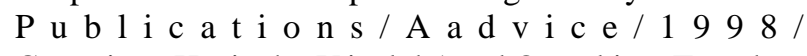

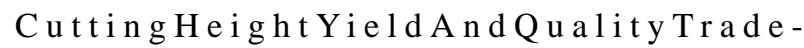
OffForCornSilage.html l. Acesso em: 10 jun. 2001.
MELO, W. M. C.; PINHO, R. G. von; CARVALHO, M. L. M. Avaliação de cultivares de milho, para produção de silagem na região de Lavras, MG. Ciência e Agrotecnologia, Lavras, v. 23, n. 1, p. 31-39, 1998.

NUSSIO, L. G.; CAMPOS, F. P. de; DIAS, F. N. Importância da qualidade da porção vegetativa no valor alimentício da silagem de milho. In: SIMPÓSIO SOBRE PRODUÇÃO E UTILIZAÇÃO DE FORRAGENS CONSERVADAS, 1. , Maringá, 2001. Anais... Maringá: Universidade Estadual de Maringá, 2001. p. 127-145.

PEREIRA, O. G. et al. Produtividade de uma variedade de milho (Zea mays L.) e de três variedades de sorgo (Sorghum bicolor (L.) Moench) e o valor nutritivo de suas silagens. Revista da Sociedade Brasileira de Zootecnia, Viçosa, v. 22, n. 1, p. 31-38, 1997.

PIONEER SEMENTES. Silagem de milho. 2. ed. Santa Cruz do Sul, 1993. (Informe técnico, 6).

PIONNER SEMENTES. Súmula técnica. Santa Cruz do Sul, 1996. 20 p. (Informe técnico, 2).

REZENDE, J. A. Características agronômicas e químicas correlacionadas à degradabilidade "in situ" de cultivares de sorgo. 2001. 53 p. Dissertação (Mestrado em Zootecnia) - Universidade Federal de Lavras, Lavras, 2001.

SAS INSTITUTE. SAS user's guide: statistics. 5. ed. Cary, 1995. $1290 \mathrm{p}$.

SOEST, P. J. van; ROBERTSON, J. B.; LEWIS, B. A. Methods for dietary fiber, neutral detergent fiber, and nonstarch polysaccharides in relation to animal nutrition. Journal of Dairy Science, Champaign, v. 74, n. 10, p. 35833597, Oct. 1991.

STAPLES, C. R. Corn silage for dairy cows. In: WEBB, D. W. (Coord.). Dairy science handbook. Gainesville: University of Florida, 1994. p. 61-65.

VILLELA, T. E. A.Época de semeadura e de corte de plantas de milho para silagem. 2001. 80 p. Dissertação (Mestrado em Fitotecnia) - Universidade Federal de Lavras, Lavras, 2001. 